\title{
Anthropometric Characteristics of Elite U/18 Sevens Rugby Players: A Focus on Positional Status
}

\author{
J. Hans DE RIDDER*, Pieter H. VAN DEN BERG, Andries ZANDBERG, Retief BROODRYK \\ Physical Activity, Sport and Recreation Research Focus Area (PhASRec), Faculty of Health Sciences, North- \\ West University, Potchefstroom, 2531, South Africa
}

*Corresponding Author: J. Hans DE RIDDER, Ph.D. Director and Professor School of Human Movement Sciences North-West University, Potchefstroom Campus Potchefstroom, 2520 SOUTH AFRICA

\begin{abstract}
:
Background: The purpose of this study was to compile a profile of the anthropometric characteristics of elite u/18 Sevens Rugby players and to determine if any morphological differences exist between the different playing positions.

Methods: Anthropometric data were collected from 164 male elite u/18 Sevens Rugby players (17.4 \pm 0.7 years), competing in a 2 day South African schools' rugby u/18 Sevens tournament. Players underwent an anthropometric assessment whereby each player's stature, body mass, selected skinfolds, girths and breadths were measured.

Results: On average the forward players indicated superior stature, body mass, BMI, fat mass (\%) and muscle mass $(\mathrm{kg})$ values compared to backline players. All-rounder players indicated a significantly bigger flexed arm girth $(d \geq 0.9)$ and femur breadth ( $d \geq 0.8)$. Forwards were taller and heavier compared to the back line players. All playing positions yielded a dominant mesomorph somatotype among the players. Overall the Sevens Rugby players could be classified as endo-mesomorphs. The results from the current study, therefore, suggest that kinanthropometry differentiates between playing positions in under 18 elite Sevens Rugby and should therefore be considered when selecting and developing sevens players in specific playing positions.
\end{abstract}

Keywords: Sevens Rugby, somatotyping, morphology, body composition, schoolboys

Running Title: Anthropometry in schoolboy Sevens Rugby

\section{INTRODUCTION}

Since its existence as a sport, rugby has become one of the main team sports on the planet, mostly because of the large number of participants competing and also the number of spectators attending the events. The rugby world cup is presented every four years and since its inception in 1987, this competition has established itself as one of the top international sporting events in the world [1]. At the Rugby World Cup in Japan in 2019, 1.84 million tickets were sold, in addition to more than 1.13 million people filling the official fanzones and over 400,000 international visitors enjoyed the incredible hospitality of the hosts, Japan. There was an estimated worldwide broadcast audience of 400 million with a record 437 billion Yen economic impact delivered for Japan [2].

Rugby consists of different codes such as Rugby Union, Rugby League and Sevens Rugby [3,4]. During recent years the latter increased in popularity and is now played at domestic and international level around the globe [5]. With the launching of the Rugby Sevens World Cup [6], the IRB World Sevens Series and acquiring Olympic status for the 2016 games, Sevens has become one of the fastest growing sport codes in recent years [4]. Sevens is seen as beneficial to younger players, because it serves as a development platform to progress to professional and international Rugby Union [7]. Both Rugby Union and Sevens Rugby are contact orientated team sports [3] and are subjected to large amounts of physical collisions such as tackling, hitting rucks and scrummaging [8]. It is possible that some physical characteristics may be deemed almost compulsory in order to achieve success, especially in collision type sports were deficiencies in anthropometric profiles may uncover weaknesses $[6,9]$. 
Existing anthropometric research on Sevens is lacking when compared to existing literature in Rugby Union and Rugby League [10]. Both Union and League codes have used anthropometry to select players and anticipate on field performance $[10,11,12,13,14,15,16,17,18]$. Nonetheless, research on Sevens [19] indicated an evolution of physique in Sevens players' stature and body mass [6,20], which might be an indication of the demands in the game evolving over the years [21]. Positional dissimilarities also emerged, with research discovering forward and backline players to exhibit different anthropometric qualities and that a specific physique might be related to a certain player position $[6,10,21]$.

In Rugby Union players are usually divided into forward and backline players when position-specific differences are investigated [22, 23]. However, due to the small number of players $(n=12)$ available to coaches at sevens tournaments, along with the frequency of matches on each day and on consecutive days, players are sometimes required to act as both forward and backline players during a tournament. Understandably, players that act as both forward and backline players during a tournament will not be able to attend both positional specific training sessions and therefore, we assert that a third category of player position need to be established known as all-rounders.

With this in mind, the aim of this study was firstly to compile a profile of the anthropometric characteristics of elite $\mathrm{u} / 18$ Sevens players and secondly to compare the anthropometric characteristics in the different playing positions. This information might be usefull to coaches and selectors during the selection process of schoolboy Sevens teams attending a tournament. It might also assist coaches in predicting the ability of players to adapt to another player position in the team.

\section{Materials AND Methods}

\subsection{Experimental Design}

In this study, a quantitative cross-sectional research design was used to determine the anthropometric characteristics of elite schoolboy Sevens Rugby players. The anthropometrical characteristics between forwards, backs and all-rounders were compared. All the players underwent anthropometric assessment in which each player's stature, body mass, selected skinfolds, girths and breadths measurements were collected.

\subsection{Participants}

A total of 164 elite male adolescent Sevens players $(\bar{X}=17.4$ years, \pm 0.7$)$ representing fifteen provincial teams from South Africa and one international team from Namibia were measured. All participants played in the South African Schools' Rugby Association u/18 Sevens tournament in October 2014. The players were categorized into forwards $(\mathrm{N}=61)$, backs $(\mathrm{N}=91)$, and all-rounders $(\mathrm{N}=12)$. The forwards consisted of props and hookers; the backs were the scrumhalves, first receivers, centres and wings; whereas the all-rounders were formed out of players able to either play as a forward or a back.

\subsection{Ethical Oversight}

Ethical permission was granted by the Etical Committee of the North-West University, Potchefstroom Campus in South Africa (NWU-00122-11-A1). The methods were explained to the players, and each participated on a voluntary basis with the option to withdraw at any stage. All participants completed a written consent form. Additionally players younger than 18 years provided written consent from their parents or a legal guardian.

\subsection{Procedures And Measures}

All the anthropometric measurements (stature, body mass, skinfolds, girths and breadths) were measured in succession to avoid experimenter bias. Two measurements were taken at each site and the mean value was used. Under ISAK protocol, the right side of the body was used for the measurements [24]. Subjects were measured by trained level II anthropometrists, following the standard procedures of the International Society for the Advancement of Kinanthropometry [24]. Subjects were requested to present themselves in minimal clothing for measurements to be made as quickly and efficiently as possible [24].

Body mass was measured with the weight evenly distributed on a calibrated electronic scale (Precision, A\&D Company, Saitama, Japan) to the nearest $0.1 \mathrm{~kg}$. Stretch stature with the head in the 
Frankfort plane [24], was measured with a Seca213 stadiometer (Seca equipment, Hamburg, Germany) to the nearest $0.1 \mathrm{~cm}$. Skinfolds $(\mathrm{mm})$ were measured to the nearest $0.2 \mathrm{~mm}$ on six different sites, namely the triceps, subscapular, supraspinale, abdominal, thigh and calf skinfolds [23], using a Harpenden skinfold caliper (10 g. $\left.\mathrm{mm}^{-2}\right)$ (Baty International, West Sussex, UK). Breadths $(\mathrm{cm})$ were determined at four different sites, namely the femur, humerus, wrist and ankle breadths [24]. Bone calipers (Cescorf Equipment, Porto Alegre, Brazil) were used to measure the breadths to the nearest $0.1 \mathrm{~cm}$. The forearm-, mid-thigh- and calf girths were measured using a flexible steel tape (Cescorf Equipment, Porto Alegre, Brazil) to the nearest $0.1 \mathrm{~cm}[24]$.

Body Mass Index was calculated as body mass $/$ stature $^{2}\left(\mathrm{~kg} / \mathrm{m}^{2}\right)$. For the sum of the six skinfolds $\left(\sum 6\right.$ skinfolds) the triceps, subscapular, supraspinale, abdominal, thigh and calf skinfolds were used. Body fat percentages were obtained by means of the equation of Withers et al. (1987) [25]. The equations of Martin et al. (1990) [26] and Martin (1991) [27] were use respectively to calculate Muscle Mass and Skeleton Mass. The equations of Carter and Heath (1990) [28] were used to calculate the somatotypes to the nearest 0.1 for all three the components (Endomorphy, Mesomorphy and Ectomorphy). Endomorphy was calculated with a height correction.

\subsection{Statistical Analysis}

The Statistical Data Processing package [29], was used for the statistical analysis of the data. All data are reported as mean \pm standard deviation (SD). One-way analyses of variance (ANOVA) were computed for comparisons between the players in the different playing position. The probability level of $\leq 0.001$ was set to determine statistical significance. Due to the pragmatic nature of the study (all players participated without random selection), Cohens's effect size (ES) were used to determine practical significance and interpreted as follow: high practical significance, $d \geq 0.8^{* *}$; medium practical significance, $d \geq 0.5^{*}$; low practical significance, $\mathrm{d} \geq 0.2$ [30].

\section{RESULTS}

The comparison of anthropometric data between the forwards, the backs and the all-round players are summarized in Table 1. The results of the one-way analyses of variance (ANOVA), grouped for comparisons between the three playing positions, showed statistically significant differences $(\mathrm{p} \leq 0.001)$ for all the girths, breadths and skinfolds.

Table 1. Comparison of anthropometric characteristics between different playing positions in elite u/18 Sevens Rugby players.

\begin{tabular}{|c|c|c|c|c|c|c|c|c|c|c|c|c|}
\hline \multirow{2}{*}{$\begin{array}{l}\text { Anthropometric } \\
\text { variables }\end{array}$} & \multicolumn{2}{|c|}{$\begin{array}{l}\text { Total } \\
\mathrm{N}=164\end{array}$} & \multicolumn{2}{|c|}{$\begin{array}{l}\text { Forwds } \\
\mathrm{N}=61\end{array}$} & \multicolumn{2}{|c|}{$\begin{array}{l}\text { Backs } \\
\mathrm{N}=91\end{array}$} & \multicolumn{2}{|c|}{$\begin{array}{l}A-R \\
N=12\end{array}$} & \multirow{2}{*}{$\begin{array}{l}\text { Forwds } \\
\text { vs. } \\
\text { Backs } \\
\text { ES }\end{array}$} & \multirow{2}{*}{$\begin{array}{l}\text { Forwds } \\
\text { vs. } \\
\text { A-R } \\
\text { ES }\end{array}$} & \multirow{2}{*}{$\begin{array}{l}\text { Backs } \\
\text { vs. } \\
\text { A-R } \\
\text { ES }\end{array}$} & \multirow{2}{*}{$\begin{array}{l}\text { ANOVA } \\
\text { Between } \\
\text { positions } \\
p \text {-value }\end{array}$} \\
\hline & $\bar{X}$ & $\begin{array}{l} \pm \\
\text { SD }\end{array}$ & $\overline{\bar{X}}$ & $\begin{array}{l} \pm \\
\mathrm{SD}\end{array}$ & $\bar{X}$ & $\begin{array}{l} \pm \\
\text { SD }\end{array}$ & $\bar{X}$ & $\begin{array}{l} \pm \\
\text { SD }\end{array}$ & & & & \\
\hline $\begin{array}{l}\text { Flexed } \\
\text { girth }(\mathrm{cm})\end{array}$ & 35.9 & $\begin{array}{l} \pm \\
2.6\end{array}$ & 37.5 & $\begin{array}{l} \pm \\
2.4\end{array}$ & 34.7 & $\begin{array}{l} \pm \\
2.3 \\
\end{array}$ & 36.7 & $\begin{array}{l} \pm \\
1.0\end{array}$ & $1.2 * *$ & 0.3 & $0.9 * *$ & $\leq 0.001$ \\
\hline Calf girth $(\mathrm{cm})$ & 37.9 & $\begin{array}{l} \pm \\
2.5 \\
\end{array}$ & 39.5 & $\begin{array}{l} \pm \\
2.1 \\
\end{array}$ & 36.8 & $\begin{array}{l} \pm \\
2.3 \\
\end{array}$ & 38.4 & $\begin{array}{l} \pm \\
1.7 \\
\end{array}$ & $1.2 * *$ & $0.5 *$ & $0.7 *$ & $\leq 0.001$ \\
\hline $\begin{array}{l}\text { Forearm girth } \\
(\mathrm{cm})\end{array}$ & 29.3 & $\begin{array}{l} \pm \\
1.7\end{array}$ & 30.3 & $\begin{array}{l} \pm \\
1.4\end{array}$ & 28.5 & $\begin{array}{l} \pm \\
1.6\end{array}$ & 29.6 & $\begin{array}{l} \pm \\
0.8\end{array}$ & $1.2 * *$ & $0.5^{*}$ & $0.7 *$ & $\leq 0.001$ \\
\hline $\begin{array}{l}\text { Mid-thigh girth } \\
(\mathrm{cm})\end{array}$ & 57.2 & $\begin{array}{l} \pm \\
4.3 \\
\end{array}$ & 59.9 & $\begin{array}{l} \pm \\
2.8 \\
\end{array}$ & 55.1 & $\begin{array}{l} \pm \\
4.2 \\
\end{array}$ & 59.2 & $\begin{array}{l} \pm \\
2.7 \\
\end{array}$ & $1.2 * *$ & 0.3 & $1.0 * *$ & $\leq 0.001$ \\
\hline $\begin{array}{l}\text { Humerus } \\
\text { breadth }(\mathrm{cm})\end{array}$ & 7.1 & $\begin{array}{l} \pm \\
0.5 \\
\end{array}$ & 7.3 & $\begin{array}{l} \pm \\
0.4 \\
\end{array}$ & 6.9 & $\begin{array}{l} \pm \\
0.5 \\
\end{array}$ & 7.1 & $\begin{array}{l} \pm \\
0.4 \\
\end{array}$ & $0.8 * *$ & $0.6^{*}$ & 0.2 & $\leq 0.001$ \\
\hline $\begin{array}{l}\text { Femur breadth } \\
(\mathrm{cm})\end{array}$ & 9.7 & $\begin{array}{l} \pm \\
0.7 \\
\end{array}$ & 10.1 & $\begin{array}{l} \pm \\
0.7\end{array}$ & 9.4 & $\begin{array}{l} \pm \\
0.6\end{array}$ & 10.0 & $\begin{array}{l} \pm \\
0.8\end{array}$ & $1.0 * *$ & 0.1 & $0.8 * *$ & $\leq 0.001$ \\
\hline $\begin{array}{l}\text { Wrist breadth } \\
(\mathrm{cm})\end{array}$ & 5.9 & $\begin{array}{l} \pm \\
0.3 \\
\end{array}$ & 6.0 & $\begin{array}{l} \pm \\
0.3\end{array}$ & 5.8 & $\begin{array}{l} \pm \\
0.3\end{array}$ & 5.8 & $\begin{array}{l} \pm \\
0.4\end{array}$ & $0.7 *$ & $0.6^{*}$ & 0.0 & $\leq 0.001$ \\
\hline $\begin{array}{l}\text { Ankle breadth } \\
(\mathrm{cm})\end{array}$ & 7.4 & $\begin{array}{l} \pm \\
0.5\end{array}$ & 7.5 & $\begin{array}{l} \pm \\
0.4\end{array}$ & 7.2 & $\begin{array}{l} \pm \\
0.4\end{array}$ & 7.5 & $\begin{array}{l} \pm \\
0.7\end{array}$ & $0.7 *$ & 0.0 & 0.4 & $\leq 0.001$ \\
\hline $\begin{array}{l}\text { Tricep skinfold } \\
(\mathrm{mm})\end{array}$ & 9.1 & $\begin{array}{l} \pm \\
3.2\end{array}$ & 10.3 & $\begin{array}{l} \pm \\
3.3\end{array}$ & 8.1 & $\begin{array}{l} \pm \\
2.9\end{array}$ & 10.1 & $\begin{array}{l} \pm \\
3.5\end{array}$ & $0.7 *$ & 0.1 & $0.6^{*}$ & $\leq 0.001$ \\
\hline $\begin{array}{l}\text { Subscapular SF } \\
(\mathrm{mm})\end{array}$ & 9.3 & $\begin{array}{l} \pm \\
2.3 \\
\end{array}$ & 10.5 & $\begin{array}{l} \pm \\
2.5\end{array}$ & 8.4 & $\begin{array}{l} \pm \\
1.6 \\
\end{array}$ & 10.2 & $\begin{array}{l} \pm \\
2.5 \\
\end{array}$ & $0.8 * *$ & 0.1 & $0.7 *$ & $\leq 0.001$ \\
\hline
\end{tabular}




\begin{tabular}{|c|c|c|c|c|c|c|c|c|c|c|c|c|}
\hline $\begin{array}{l}\text { Supraspinal SF } \\
(\mathrm{mm})\end{array}$ & 7.9 & $\begin{array}{l} \pm \\
3.3\end{array}$ & 9.5 & $\begin{array}{l} \pm \\
3.9\end{array}$ & 6.7 & $\begin{array}{l} \pm \\
2.2\end{array}$ & 9.1 & $\begin{array}{l} \pm \\
3.8\end{array}$ & $0.7 *$ & 0.1 & $0.6^{*}$ & $\leq 0.001$ \\
\hline $\begin{array}{l}\text { Abdominal SF } \\
(\mathrm{mm})\end{array}$ & 13.4 & $\begin{array}{l} \pm \\
6.6\end{array}$ & 16.6 & $\begin{array}{l} \pm \\
7.8\end{array}$ & 10.8 & $\begin{array}{l} \pm \\
4.1\end{array}$ & 16.2 & $\begin{array}{l} \pm \\
7.9\end{array}$ & $0.7 *$ & 0.1 & $0.7 *$ & $\leq 0.001$ \\
\hline $\begin{array}{l}\text { Front thigh SF } \\
(\mathrm{mm})\end{array}$ & 12.4 & $\begin{array}{l} \pm \\
5.4\end{array}$ & 15.1 & $\begin{array}{l} \pm \\
5.7\end{array}$ & 10.6 & $\begin{array}{l} \pm \\
4.4\end{array}$ & 13.0 & $\begin{array}{l} \pm \\
5.1\end{array}$ & $0.8 * *$ & 0.4 & $0.5^{*}$ & $\leq 0.001$ \\
\hline $\begin{array}{l}\text { Medial calf SF } \\
(\mathrm{mm})\end{array}$ & 8.2 & $\begin{array}{l} \pm \\
2.8\end{array}$ & 9.6 & $\begin{array}{l} \pm \\
2.9\end{array}$ & 7.3 & $\begin{array}{l} \pm \\
2.3\end{array}$ & 8.7 & $\begin{array}{l} \pm \\
3.4\end{array}$ & $0.8 * *$ & 0.3 & 0.4 & $\leq 0.001$ \\
\hline
\end{tabular}

Note: $\bar{X}$, mean; SD, standard deviation; high practical significance, $\mathrm{d} \geq 0.8 * *$; medium practical significance, $\mathrm{d} \geq 0.5 *$; low practical significance, $\mathrm{d} \geq 0.2$. Forwds $=$ Forwards; $A-\mathrm{R}=$ All-rounders

Girths. The forwards showed, as expected, larger values in all four the girth measurements (flexed arm, calf, forearm and mid-thigh), than the backs. Each of these comparisons showed large univariate effect sizes $\left(d \geq 0.8^{* *}\right)$. Comparing the forwards to the all-rounders, only moderate effect sizes were found in the calf and forearm girths $\left(\mathrm{d} \geq 0.5^{*}\right)$ where the girths of the forwards were larger than those of the all-rounders. Although the forwards had larger arm and mid-thigh girths than the all-rounders, only small effect sizes were found. Between the backs and the all-rounders, comparisons showed large univariate effect sizes $\left(\mathrm{d} \geq 0.8^{* *}\right)$ for the arm and mid-thigh girths with the backs having smaller girths than the all-rounders. The calf and forearm girths showing moderate univariate effect sizes $\left(\mathrm{d} \geq 0.5^{*}\right)$, again with the all-rounders having larger girths than the backs.

Breadths. As expected, the forwards showed larger breadths in all four the breadth measurements (humerus, femur, wrist, ankle) than the backs. In both the humerus and femur breadths, the comparisons showed large univariate effect sizes $\left(d \geq 0.8^{* *}\right)$, with the other two breadths, wrist and ankle, which showed moderate univariate effect sizes $\left(\mathrm{d} \geq 0.5^{*}\right)$ between forwards and backs. Although the forwards showed larger values in three of the four breadth measurements than the all-rounders, only two of these breadths (humerus and wrist) showed moderate univariate effect sizes $\left(\mathrm{d} \geq 0.5^{*}\right)$. With the other two breadths (femur and ankle) only low practical effect sizes were found. The femur breadth of the all-rounders were larger than those of the backs and also showed large univariate effect sizes $\left(\mathrm{d} \geq 0.8^{* *}\right)$. With regard to the other three breadths (humerus, wrist, ankle) only small effect sizes were found between the backs and the all-rounders.

Skinfolds. As was the case with the girths as well as the breadths, the forwards showed bigger values with regard to all six the skinfolds, than the backs. Three of the skinfolds (subscapular, thigh and calf) showed large univariate effect sizes $\left(\mathrm{d} \geq 0.8^{* *}\right)$. The other three skinfolds (triceps, supraspinale and abdominal), showed moderate univariate effect sizes $\left(\mathrm{d} \geq 0.5^{*}\right)$ between forwards and backs. Although the forwards showed bigger skinfold values than the all-rounders, low effect sizes were found with regard to all six the skinfolds. In the comparison between the backs and the all-rounders, the latter group had the bigger skinfold values with five of the six skinfolds (triceps, subscapular, supraspinale, abdominal and thigh) that showed moderate univariate effect sizes $\left(\mathrm{d} \geq 0.5^{*}\right)$ and calf skinfold showing low effect sizes between the backs and the all-rounders.

Table 2 is the comparison of body composition between the different playing positions.

Table 2. Comparison of the body composition between different playing positions in elite u/l8 Sevens Rugby players.

\begin{tabular}{|c|c|c|c|c|c|c|c|c|c|c|c|c|}
\hline \multirow{3}{*}{$\begin{array}{l}\text { Body } \\
\text { composition }\end{array}$} & \multirow{2}{*}{\multicolumn{2}{|c|}{$\begin{array}{l}\text { Total } \\
\mathrm{N}=164\end{array}$}} & \multirow{2}{*}{\multicolumn{2}{|c|}{\begin{tabular}{|l} 
Forwds \\
$\mathrm{N}=61$
\end{tabular}}} & \multirow{2}{*}{\multicolumn{2}{|c|}{$\begin{array}{l}\text { Backs } \\
\mathrm{N}=91\end{array}$}} & \multirow{2}{*}{\multicolumn{2}{|c|}{$\begin{array}{l}A-R \\
N=12\end{array}$}} & \multirow{3}{*}{\begin{tabular}{|l|} 
Forwds \\
vs. \\
Backs \\
ES
\end{tabular}} & \multicolumn{2}{|c|}{ Forwds Backs } & \multirow{3}{*}{\begin{tabular}{|l|} 
ANOVA \\
Between \\
positions
\end{tabular}} \\
\hline & & & & & & & & & & vs. & vs. & \\
\hline & $\overline{\bar{X}}$ & $\pm \mathrm{SD}$ & $\bar{X}$ & $\pm \mathrm{SD}$ & $\bar{X}$ & $\pm \mathrm{SD}$ & $\bar{X}$ & $\pm \mathrm{SD}$ & & $\mathrm{ES}$ & $\mathrm{ES}$ & \\
\hline Age (years) & 17.4 & \pm 0.7 & 17.5 & \pm 0.6 & 17.3 & \pm 0.7 & 17.6 & \pm 0.5 & 0.3 & 0.3 & $0.5^{*}$ & 0.87 \\
\hline Stature $(\mathrm{cm})$ & 176.8 & \pm 6.9 & 180.9 & \pm 6.2 & 173.8 & \pm 6.0 & 179.2 & \pm 4.6 & $1.1 * *$ & 0.3 & $0.9 * *$ & $\leq 0.001$ \\
\hline $\begin{array}{ll}\text { Body } & \text { mass } \\
(\mathrm{kg}) & \end{array}$ & 79.3 & \pm 10.5 & 87.8 & \pm 8.1 & 73.0 & \pm 7.7 & 84.5 & \pm 6.6 & $1.8 * *$ & 0.4 & $1.5 * *$ & $\leq 0.001$ \\
\hline BMI $\left(\mathrm{kg} / \mathrm{m}^{2}\right)$ & 25.3 & \pm 2.4 & 26.8 & \pm 2.2 & 24.2 & \pm 2.0 & 26.3 & \pm 1.5 & $1.2 * *$ & 0.3 & $1.1 * *$ & $\leq 0.001$ \\
\hline Body fat (\%) & 10.0 & \pm 3.2 & 11.7 & \pm 3.4 & 8.7 & \pm 2.3 & 10.9 & \pm 3.8 & $0.9 * *$ & 0.2 & $0.6^{*}$ & $\leq 0.001$ \\
\hline$\sum_{(\mathrm{mm})} 6$ skinfolds & 60.3 & \pm 20.9 & 71.6 & \pm & 51.9 & $\begin{array}{l} \pm \\
14.8\end{array}$ & 67.3 & \pm 24.3 & $0.9 * *$ & 0.2 & $0.6^{*}$ & $\leq 0.001$ \\
\hline $\begin{array}{l}\text { Skeletal mass } \\
(\mathrm{kg})\end{array}$ & 9.7 & \pm 1.3 & 10.5 & \pm 1.2 & 9.1 & \pm 1.0 & 10.0 & \pm 1.4 & $1.2 * *$ & 0.3 & $0.7 *$ & $\leq 0.001$ \\
\hline $\begin{array}{l}\text { Muscle mass } \\
\text { (kg) }\end{array}$ & 47.3 & \pm 6.8 & 51.8 & \pm 5.4 & 43.9 & \pm 6.0 & 50.2 & \pm 3.4 & $1.3 * *$ & 0.3 & $1.1 * *$ & $\leq 0.001$ \\
\hline
\end{tabular}


Note: $\bar{X}$, mean; SD, standard deviation; high practical significance, $\mathrm{d} \geq 0.8 * *$; medium practical significance, $\mathrm{d} \geq 0.5 *$; low practical significance, $\mathrm{d} \geq 0.2$. Forwds $=$ Forwards; $A-\mathrm{R}=$ All-rounders.

Although the all-rounders were the oldest group (17.6 years) and the backs the youngest (17.3 years), there was no statistical significant difference $(\mathrm{p}=0.87)$ between the three groups with regard to age. The backs were only moderate younger (practical significant difference $\left(d \geq 0.5^{*}\right)$ than the all-rounders (see Table 2).

Both the basic measurements namely stature and body mass, indicated a statistically significant difference $(\mathrm{p} \leq 0.001)$ between the players in the three playing positions. As expected the forwards were the tallest as well as the heaviest group of players. Although the differences between forwards and backs showed a high practical significance $\left(\mathrm{d} \geq 0.8^{* *}\right)$, the differences between forwards and all-rounders only had a low practical significance for both stature and body mass. A high practical significance $(\mathrm{d} \geq 0.8 * *)$ were found for stature as well as body mass between the backs and the all-rounders with the latter the taller and heavier group of the two.

According to Table 2, all the body composition variables, showed a statistical significant difference between the three groups of players. Between the forwards and the backs a high practical significance $\left(d \geq 0.8^{* *}\right)$ were found for percentage body fat, sum of the six skinfolds, skeletal mass $(\mathrm{kg})$ and muscle mass $(\mathrm{kg})$. For BMI a moderate practical significant differences occurred $(\mathrm{d} \geq 0.5 *)$ between the forwards and the backs. The comparison between the forwards and the all-rounders showed a low practical significance for all the body composition variables. With regard to the comparison between backs and the all rounders, there was a high practical significance $(\mathrm{d} \geq 0.8 * *)$ for BMI as well as muscle mass. The rest of the variables (percentage body fat, sum of the six skinfolds and skeletal mass), had moderate practical significant differences $\left(\mathrm{d} \geq 0.5^{*}\right)$.

The somatotypes of the different playing positions of the $\mathrm{u} / 18$ Sevens Rugby players are presented in Table 3.

Table 3. Comparison of the somatotype classification between the different playing positions in elite $u / 18$ Sevens Rugby players.

\begin{tabular}{|c|c|c|c|c|c|c|c|c|c|c|c|c|}
\hline \multirow{2}{*}{$\begin{array}{l}\text { Somatotype } \\
\text { components }\end{array}$} & \multicolumn{2}{|c|}{$\begin{array}{l}\text { Total } \\
\mathrm{N}=164\end{array}$} & \multicolumn{2}{|c|}{$\begin{array}{l}\text { Forwds } \\
\mathrm{N}=61\end{array}$} & \multicolumn{2}{|c|}{$\begin{array}{l}\text { Backs } \\
\mathrm{N}=91\end{array}$} & \multicolumn{2}{|c|}{$\begin{array}{l}\text { A-R } \\
N=12\end{array}$} & \multirow{2}{*}{\begin{tabular}{|l} 
Forwds \\
vs. \\
Backs
\end{tabular}} & \multirow{2}{*}{\begin{tabular}{|l|} 
Forwds \\
vs. \\
A-R \\
ES \\
\end{tabular}} & \multirow{2}{*}{\begin{tabular}{|l} 
Backs \\
vs. \\
A-R \\
ES \\
\end{tabular}} & \multirow{2}{*}{$\begin{array}{l}\text { ANOVA } \\
\text { Between } \\
\text { positions }\end{array}$} \\
\hline & $\bar{X}$ & \pm SD & $\bar{X}$ & $\pm \mathrm{SD}$ & $\bar{X}$ & $\pm \mathrm{SD}$ & $\bar{X}$ & \pm SD & & & & \\
\hline Endomorphy & 2.9 & \pm 1.0 & 3.4 & \pm 1.1 & 2.6 & \pm 0.8 & 3.3 & \pm 1.2 & $0.7 *$ & 0.1 & $0.6^{*}$ & $\leq 0.001$ \\
\hline Mesomorphy & 5.8 & \pm 1.1 & 6.2 & \pm 1.2 & 5.5 & \pm 1.1 & 5.9 & \pm 0.8 & $0.6^{*}$ & 0.3 & 0.3 & $\leq 0.001$ \\
\hline Ectomorphy & 1.7 & \pm 0.8 & 1.4 & \pm 0.8 & 2.0 & \pm 0.8 & 1.4 & \pm 0.5 & $0.7^{*}$ & 0.0 & $0.7^{*}$ & $\leq 0.001$ \\
\hline
\end{tabular}

Note: $\bar{X}$, mean; SD, standard deviation; high practical significance, $\mathrm{d} \geq 0.8 * *$; medium practical significance, $\mathrm{d} \geq 0.5 *$; low practical significance, $\mathrm{d} \geq 0.2$. Forwds $=$ Forwards; $A-\mathrm{R}=$ All-rounders.

The total group $(n=164)$ of Sevens players in this study was dominant mesomorphs and can be classified as endomorphic mesomorphs $(\bar{X}=2.9-5.8-1.7)$. The forwards as well as the allrounders were also endomorphic mesomorphs (forwards: $\bar{X}=3.4-6.2-1.4$ and all-rounders: $\bar{X}=$ $3.3-5.9-1.4)$. Although the backs were also classified as endomorphic mesomorphs $(\bar{X}=2.6-5.5$ - 2.0), they are very close being classified as balanced mesomorphs. Al three the somatotype components (endomorphy, mesomorphy and ectomorphy) indicated a statistically significant difference $(p \leq 0.001)$ between the players in the three playing positions. Between the forwards and the backs there were moderate practical significant differences $\left(\mathrm{d} \geq 0.5^{*}\right)$ for all three the somatotype components with the forwards more dominant in both the mesomorhy as well as the endomorphy than the backs. Between the forwards and the all-rounders the practical significant differences for all three the components, were low. With regard to the comparison between the backs and the all-rounders, the latter group were more dominant in both the mesomorhy as well as the endomorphy. There were moderate practical significant differences $\left(\mathrm{d} \geq 0.5^{*}\right)$ for endomorhy as well as ectomorphy between the backs and the all-rounders.

\section{DISCUSSION}

The aim of this investigation was firstly to compile a profile of the anthropometric characteristics of elite $\mathrm{u} / 18$ Sevens Rugby players and secondly to compare the anthropometric characteristics in the 
different playing positions. The results indicated that anthropometric characteristics and body composition of $\mathrm{u} / 18$ elite Sevens players, differ between playing positions with the majority of differences occuring between backs and forwards.

The forwards in this study, were significant taller and heavier than the backs and also had significant larger girths in all four the measurements. The forwards also showed significant larger breadths in all four breadth measurements as well as the six skinfolds, than the backs. With regard to body composition, the forwards had a significant larger BMI, percentage body fat as well as sum of 6 skinfolds than the backs. They also showed significant larger skeletal mass as well as muscle mass (measured in kilograms), than the backs. As expected, the forwards had significant larger endomorphic as well as mesomorphic values than the backs with the latter having a significant larger ectomorphic value than the forwards. Both the backs and the forwards were classified as endomorphic mesomorphs.

Anthropometric differences between forward and backline players were also observed by similar age groups of Rugby Union players [31, 32, 33] as well as Rugby League players [34]. Supporting literature done on Sevens regarding playing positions, also discovered forward players to present significantly greater values for stature, body mass $[6,10,21]$ and larger fat- and muscle masses $[6,10]$ than backline players. However, differences between forwards and backs in Sevens were considerably less than comparisons between forwards and backs from Rugby Union [10]. The difference between forwards and backs, could be explained due to the fact that forward players should be bigger and heavier than backline players in order to gain an advantage during scrums and rucks, who contest a greater frequency of restart attempts, participate in lineouts, as well as phases of play where forward players are reasonably more involved in than backline players [6, 35]. On the other hand, a lighter body mass is more beneficial to backs in order to evade opponents by accelerating and sprinting at higher speeds $[9,10,35]$.

The all-rounders differed to a lesser extent to both the forwards and backs, which were expected, as they have the ability to be either a forward or a back. Comparing to the backs, the all-rounders were significant taller and heavier than the backs. The all-rounders also had significant larger girth measurements than the backs, but smaller girths than the forwards with the calf- and forearm girths significant smaller. In three of the four breadths the all-rounders showed larger values than the backs with only the femur breadth reaching a level of significance. Although the forwards showed larger breadths in three of the four measurements in comparison to the all-rounders, only the humerus- and wrist breadths were significant larger.

With regard to the skinfolds, the all-rounders had significant larger values for all six the skinfolds than the backs, while similar values were observed among the forwards. As a result the all-rounders had significant higher BMI values compared to only the backs and not the forwards. The same trend transpired concerning the $\%$ body fat, sum of 6 skinfolds, skeletal- as well as muscle mass where the all-rounders again showed larger values than that of the backs. They had non-significant smaller values in these variables than the forwards. Although the forwards had larger endo- as well as mesomorphic values than the all-rounders this wasn't significant. The all-rounders had a significant larger endomorphic component than that of the backs. The backs had the largest ectomorphic component, with the forwards and all-rounders having the same value. The all-rounders were classified as endomorphic mesomorphs.

All-rounders have the ability to be used either as forward or backline players, which explains the bigger body size, than that of the backs. No significant differences between forwards and all-rounders worth mentioning, were found. The current findings suggest that the significant differences in the anthropometric features between different playing positions of this particular study, might indicate that positional roles in Sevens are subjected to a specific physique. Regarding somatotype, the forwards, backs and all-rounders were all classified as endomorphic mesomorphs. This is consistent with the literature that reported Sevens forward and backline players to be endomorphic mesomorphs [6].

Despite all the positions having an endomorphic mesomorph type of physique, the forwards still had significant larger endomorphic as well as mesomorphic values than the backs. Altough the forwards had slightly larger endo- and mesomorphic values as the all-rounders, their somatotypes were very similar. According to research, individuals with an endomorphic mesomorph somatotype have greater strength and power than either balanced mesomorphs or ectomorphic mesomorphs, which is very 
advantageous when competing for the ball in scrums, rucks and mauls [36]. Due to the contact orientated nature of Sevens, it seems therefore that an endomorphic mesomorph somatotype is beneficial and emphasize the fact that an all-rounder can play either as a forward or a backline player. Anthropometric characteristics such as those used in this study, may be useful for Sevens coaches for program design, team selection and talent identification [10].

\section{Practical Applications}

This study is the first to compile an anthropometric profile and also to describe the differences between the different playing positions of elite $\mathrm{u} / 18$ Sevens players regarding their anthropometric and body composition characteristics. From the findings of this study, it is clear that although there are differences in the anthropometric characteristics between the three different playing positions, there is also a similarity in their somatotypes. All three the positions are classified as endomorphic mesomorphs indicating that similar body types exist among Sevens schoolboy players. Therefore position-specific programs to develop a specific anthropometric profile, are likely not required in schoolboy Sevens Rugby and coaches should instead focus on improving individual strengths and weaknesses [10]. The anthropometric differences can be utilised to guide coaches and selectors when choosing players for specific playing positions or more specifically, to clarify whether a certain backline player might be able to also play as a forward or vice versa.

\section{ACKNOWLEDGEMENT}

The authors of this study would like to thank the South African National Lottery Distribution Trust Fund (NLDTF) that provided the financial support for the research.

\section{REFERENCES}

[1] Martin I, Olmo J, Chirosa LJ, Carreras D, Sola, J. Bibliometric study (1922-2009) on rugby articles in research journals. S Afr J Res Sport Phys Educ Recreation. 2013; 35: 105-119.

[2] Richardson J. Rugby World Cup Japan 2019 makes huge splash, shatters records. The South African. https://www.thesouthafrican.com/sport/rugby-world-cup/rugby-world-cup-japan-2019-makes-huge-splashshatters-records/. 2019.

[3] Suarez-Arrones LS, Nuñez FJ, Portillo J, and Mendez-Villanueva A. Running demands and heart rate responses in men rugby sevens. J Strength Cond Res. 2012; 26: 3155-3159.

[4] Suarez-Arrones LS, Nuñez FJ, Munguía-Izquierdo D, Portill J, Mendez-Villanueva A. Impact of several matches in a day on physical performance in rugby sevens referees. Int J Sports Physiol Perform. 2013;8: 496-501.

[5] Higham DG, Pyne DB, Anson JM, Eddy A. Movement patterns in rugby sevens: Effects of tournament level, fatigue and substitute players. J SciMedSport. 2012;15(3):277-282. doi:10.1016/j.jsams.2011.11.256

[6] Rienzi E, ReillyT, Malkin, C. Investigation of anthropometric and work-rate profiles of Rugby Sevens players. J Sports Med 39. 1999;160-164.

[7] Dziedzic CE, Higham DG. Performance nutrition guidelines for international rugby sevens tournaments. Int J Sport Nutr Exerc. 2014; 24: 305-314.

[8] Suarez-Arrones L, Arenas C, López, G, Requena, B, Terrill, O, and Mendez-Villanueva, A. Positional differences in match running performance and physical collisions in men rugby sevens. Int $J$ Sports Physiol Perform 9: 316-323, 2014.

[9] Meir R. Training for and competing in sevens rugby: practical considerations from experience in the International Rugby Board World series. Strength Cond J. 2012; 34: 76-86.

[10] Ross A, Gill ND, Cronin JB. Comparison of the anthropometric and physical characteristics of international and provincial rugby sevens players. Int J Sports Physiol Perform.2015; Sep;10(6):780-5. doi: 10.1123/ijspp.2014-0331. Epub 2014 Sep 17.

[11] Gabbett TJ. Physiological and anthropometric characteristics of amateur rugby league players. Br J Sports Med. 2000; 34: 303-307.

[12] Gabbett TJ, Kelly J, Ralph S, Driscoll D. Physiological and anthropometric characteristics of junior elite and sub-elite rugby league players, with special reference to starters and non-starters. J Sci Med Sport. 2009; $12: 215-222$.

[13] Gabbett TJ, Jenkins DG, Abernethy B. Relative importance of physiological, anthropometric, and skill qualities to team selection in professional rugby league. J Sports Sci. 2011; 29: 1453-1461.

[14] Nicholas CW. Anthropometric and physiological characteristics of rugby football players. Sports Med. 1997; 23: 375-396. 
[15] Olds T. The evolution of physique in male rugby union players in the twentieth century. J Sports Sci. 2001; 19: 253-262.

[16] Quarrie KL, Handcock P, Waller AE, Chalmers DJ, Toomey MJ, Wilson BD. The New Zealand rugby injury and performance project III. Anthropometric and physical performance characteristics of players. $\mathrm{Br}$ J Sports Med. 1995; 29: 263-270.

[17] Sedeaud A, Marc A, Schipman J, Tafflet M, Hager JP, Toussaint JF. How they won Rugby World Cup through height, mass and collective experience. Br J Sports Med. 2012;46: 580-584.

[18] Till, K, Cobley, S, O’Hara, J, Brightmore, A, Cooke, C, and Chapman, C. and. Using anthropometric and performance characteristics to predict selection in junior UK rugby league players. J Sci Med Sport 14: 264-269, 2011.

[19] Higham, DG, Pyne, DB, Anson, JM and Eddy, A. Physiological, anthropometric, and performance characteristics of rugby sevens players. Int J Sports Physiol Perform8: 19-27, 2013.

[20] Takahashi, I, Umeda, T, Mashiko, T, Chinda, D, Oyama, T, Sugawara, K, and Nakaji, S. Effects of rugby sevens matches on human neutrophil-related non-specific immunity. Br J Sports Med 41: 13-18, 2007.

[21] Fuller, CW, Taylor, A, and Molloy, MG. Epidemiological study of injuries in international rugby sevens. Clin J Sport Med 20: 179-184, 2010.

[22] Duthie, G, Pyne, D and Hooper, S. Applied Physiology and Game Analysis of Rugby Union. Sports Med 33: 973-991, 2003.

[23] Gamble P. Physical Preparation for Elite-Level Rugby Union Football. Strength Cond J. 2004;26(4):10. doi:10.1519/1533-4295(2004)026<0010:ppferu>2.0.co;2

[24] Stewart AD, Marfell-Jones MJ, Olds T, De Ridder JH. International Standards for Anthropometric Assessment, (3 ${ }^{\text {rd }}$ ed). 2011; Lower Hutt: ISAK.

[25] Withers, RT, Craig, NP, Bourdon, PC, and Norton, KI. Relative body fat and anthropometric prediction of body density of male athletes. Eur J Appl Physiol56: 191-200, 1987.

[26] Martin, AD, Spenst, LF, Drinkwater, DT, and Clarys, JP. Anthropometric estimation of muscle mass in men. Med Sci Sports Exerc 22: 729-733, 1990.

[27] Martin, AD. Anthropometric assessment of bone mineral. In: Anthropometric assessment of nutritional status. L, Himes, ed. New York: Wiley-Liss, 1991. pp. 185-196.

[28] Carter, JEL, and Heath, BH. Somatotyping: development and applications. Cambridge: Cambridge University Press, 1990.

[29] IBM Corp. Released 2013. IBMSPSS Statistics for Windows, Version 22.0. Armond, NY: IBM Corp.

[30] Cohen, J. Statistical power analysis, (2 ${ }^{\text {nd }}$ ed.). Hillsdale, NJ: Erlbaum, 1988.

[31] Delahunt, E, Byrne, RB, Doolin, RK, McInerney, RG, Ruddock, CTJ, and Green, BS. Anthropometric profile and body composition of Irish adolescent rugby union players. J Strength Cond Res 24: 3252-3258, 2014.

[32] Durandt, J, Du Toit, S, Borresen, J, Hew-Butler, T, Masimla, H, Jakoet, I, and Lambert, M. Fitness and body composition profiling of elite junior South African rugby players. South African J Sports Med 18: 38-45, 2006.

[33] Van Gent, MM and Spamer, EJ. Comparisons of positional groups in terms of anthropometric, rugbyspecific skills, physical and motor components among U13, U16, U18 and U19 elite rugby players. Kinesiology 37: 50-63, 2005.

[34] Cheng, HL, O’Connor, H, Kay, S, Cook, R., Parker, H, and Orr, R. Anthropometric characteristics of Australian junior representative rugby league players. J Sci Med Sport 17: 546-551, 2014.

[35] Rigg, P, Reilly, TA. A fitness profile and anthropometric analysis of first and second class rugby union players. In: Science and football. T. Reilly, A. Lees, K. Davids, W.J. Murphy, eds. London: Routledge Revivals, 1988. pp. 194-200.

[36] Wilders CJ, De Ridder JH. Somatotype differences in playing positions among South African Senior Provincial rugby players. African J Phys, Health Educ, Recreation Dance. 2001; Vol 7(1):51-60

Citation: J. Hans DE RIDDER. "Anthropometric Characteristics of Elite U/18 Sevens Rugby Players: A Focus on Positional Status" International Journal of Sports and Physical Education (IJSPE), vol 6, no. 3, 2020, pp. 16-23. doi: https://doi.org/10.20431/2454-6380.0603004.

Copyright: (C) 2020 Authors. This is an open-access article distributed under the terms of the Creative Commons Attribution License, which permits unrestricted use, distribution, and reproduction in any medium, provided the original author and source are credited. 